\title{
Imagen de Ricardo Rojas
}

Tuve el privilegio de tratar a Ricardo Rojas durante más de veinte
años. Había leído algunos de sus libros mientras cursaba el bachillerato en un Colegio Nacional de provincia. Le escribi una de esas cartas de muchacho, ingenua, admirativa. Rojas la respondió con generosa extensión. Al venir a Buenos Aires, mi primera visita fue a su casa de la calle Charcas. No hay nada singular en este episodio. ¡Cuántos podrían referir lo mismo! Era parte de la vida de Rojas alentar vocaciones y aconsejar a los jóvenes. A su lado, igual que otros, me formé como profesor y como escritor. Nuestra amistad, al cabo de los años, concluyó por situarse naturalmente en un plano de intimidad muy honda. Hay siempre esencias paternales en un maestro, pero la verdad es que el cariño de padre y de amigo que él prodigaba llegó a ser nuestro vínculo más cierto. Así lo sentimos muchos discípulos que quisimos filialmente a este varón tierno y generoso. Tal intimidad hace difícil trazar una imagen nítida del poeta $y$ del profeta, del ciudadano y del humanista que hizo de la Argentina una musa, una obsesión y un ideal. Aunque Rojas no hubiese escrito libro alguno, aunque no hubiese recibido honores académicos ni aplauso de multitudes, igual nos seguiría pareciendo un ejemplo de bondad, de sabiduría y de sencillez. Un ejemplo, en suma, de virtud.

No había en su discurso pasajes ociosos. Se apoyaba en lo anecdótico o en lo pintoresco para tomar impulso y zambullirnos en la médula de un pensamiento. Recuerdo cierta vez en que hizo la paradojal alabanza de un vehículo casi arqueológico: el tranvía. Rojas lo esperaba durante largos ratos, pacientemente, en la calle Santa Fe, cerca de su casa, o en la esquina de la Facultad de Filosofía y Letras. Allí su amable plática con los alumnos prolongaba las lecciones del aula. Precisamente su elogio del tranvía se vinculaba a una tesis sobre la espera y la utilidad de ésta para el ejercicio de la paciencia y de la meditación. Al censurar la prisa inútil, 
la agitación para la nada de tantos seres despojados de fines, llevaba el razonamiento a esferas más amplias y criticaba el arrebato, la furia inútil y destructora que suele sacudir a nuestra tierra. Recordaba entonces una frase de San Martín a Guido: "Los argentinos son hombres sin espera"... De lo aparentemente pasajero llegaba siempre a reflexiones sobre el país, meollo radical de su meditación.

Rojas poseyó el don de la palabra hablada y escrita. La palabra era su gran instrumento de creación. Un recuerdo de la vida en provincia o de las luchas de su padre en Santiago del Estero, la visita del joven poeta que llevaba su primer libro a Mitre, sus conversaciones con Darío y con Unamuno, todos los tópicos de ayer y de hoy se anudaban con naturalidad a una viva interpretación de la Argentina. El amor a esta tierra constituye la clave de toda su obra y, acaso, de toda su vida.

Cuando vio a la patria yacer en sombras, también su alma se llenó de tinieblas y se sintió exilado en su propia tierra. Este hombre que sufrió vetos, procesos y presidio como reo político sin dejarse ganar por la amargura, padeció abismalmente la soledad. Lo combatían con saña sus enemigos y muchas veces lo incomprendían sus propios amigos. El más constante de sus pesares era sentirse débil para conjurar el mal. Tan absoluta fue esa certidumbre de fracaso que empezó a morir de la patria. La fe que resplandece en sus libros, esa confianza en las inextinguibles reservas de nuestra tierra, en cierto instante se quebró. Creyó su lucha y su obra inútiles, y su propia existencia un sacrificio estéril. Una tarde, en enero de 1955, me dijo: "Yo no tuve patria sino como ilusión para el futuro". No se resignaba a la sima engañosa a que había caído su pueblo. Desde el fondo de su angustia sabía encontrar palabras de esperanza como éstas, que afirmaban, a pesar de todo, la existencia de la patria ideal.

La suya fue una vida hecha de donación y de amor. Rojas vivió en estado de pobreza y trabajó incansablemente. Amó a su pueblo con naturalidad y aun con inocencia. Quiso a sus amigos y a sus discípulos. En una ciudad de hombres apresurados y anhelantes, de hombres "sin tiempo", las puertas de su casa estaban abiertas y su diálogo era generoso para los compatriotas de todas las edades y de todas las condiciones. En esas charlas prolongaba la misión del libro, de la cátedra, de la militancia política.

Ricardo Rojas continúa en la Argentina la tradición de Echeverría, de Alberdi, de Sarmiento, de Mitre, de Gutiérrez, de González. Su vida y su obra podrían figurar cómodamente en las cuatro direcciones en las que estudió a los escritores del pasado argentino: Elelin, La salamanca y Ollantay 
pertenecen al ciclo de Los coloniales; El pais de la selva se vincula con la tradición de Los gauchescos; Arcbipiélago, Cervantes y $\mathrm{El}$ albatros son páginas de proscripto escritas en la prisión más austral del globo; La victoria del bombre, Las lises del blasón, sus biografías de San Martín y de Sarmiento, aquilatan la modernidad de su estilo y la constante renovación de su pensamiento.

Es sobre todo a Sarmiento a quien la índole de su obra, no obstante profundas disparidades, puede parangonarse en el plano de las esencias. Ambos son expresiones telúricas, de acusada fisonomía racial, admonitores y consejeros de su destino. Se parecen por el sentimiento de nuestra América, por la pasión educativa, por la búsqueda patética de verdades orientadoras. El vínculo unitivo de toda la prédica idealista de Rojas podría tal vez encontrarse en las variaciones sobre una prolongada respuesta a la pregunta abrumadora lanzada desde Conflictos y armonías de las razas: "Argentinos, ¿desde cuándo y hasta dónde? Bueno es darse cuenta de ello".

Al penetrar en el misterio psicológico de Sarmiento, Rojas se retrata. Describe al sanjuanino con rasgos que valen para él mismo: "Muchos lo creyeron loco y algunos lo consideraron genio. En realidad era un hombre de sensibilidad esotérica como la de un brujo huarpe". Al contemplar el rostro de Rojas, en los últimos años, la atención quedaba fascinada por sus ojos absortos, penetrantes, cuyo brillar misterioso agigantaban los cristales de sus anteojos. A su lado nacía, sin violencias, la atmósfera del mito y de la profecía. En I947, al trazar una semblanza lírica de su vida, el mismo Rojas se pregunta:

¿Quién era yo? ¿Tal vez era un amauta?

Quizá un baquiano de la travesía

o un expatriado aquí, en mi propia patria.

Personaje típico de la cultura hispanoamericana, este humanista criollo soblo se explica en función de su tiempo y de su patria. Su vocación auténtica fue la de escritor, pero poseyó un sentido militante de este oficio. Su conciencia de ciudadano lo llevó a destinos que ni deseaba ni buscó. Confiesa que cuando le of recieron el decanato de la Facultad de Filosofia y Letras se sintió como "pájaro trampeado a quien se va a enjaular".

Fue maestro incansable de argentinidad. Descendió a la entraña misteriosa de nuestro ser colectivo, en una tarea de revisión y de construcción, de examen de conciencia, de mirar hacia atrás en función de futuro. Tras la delicada serenidad de su obra se descubre en él a un temperamento fer- 
voroso. Apolíneo por la expresión, alienta en su obra la inquietud dionisíaca de América. Sentía la pasión de la vida y la pasión del estudio fundidas en una bella unidad. Hablando una vez con sus discípulos les decía: "Yo soy también, aunque soñador y cantor, hombre de vigilancia y de lucha; pero a la vez, soy un espíritu razonador, tolerante y estoico".

Hijo de Indoamérica, exaltó la belleza de las tradiciones vernáculas y se sintió orgulloso de que las multitudes lo vivasen como "el indio Rojas", pero comprendió que la cultura hispanoamericana sólo se realizaría plenamente sin aislamientos cerriles y con ancho sentido universal. Por eso escribió sobre El kakuy y $L_{a} T$ Telesita, pero también forjó los hexámetros de su Odat latina. En un quehacer titánico, a través del relato, la poesía, el drama, la historia y la crítica, ha cantado e iluminado los temas de nuestra tierra y ha puesto en claro los motivos de nuestra desdicha. Salvados matices de tiempo y circunstancias, también son aplicables a Rojas estas palabras de su biografía de Sarmiento: "Personaje armado de la palabra escrita en un pueblo analfabeto y disperso, proviene de esa desarmonía su patetismo a veces extravagante. Es un patriota desesperado que vivió en constante expatriación real o visionaria".

Desde comienzos del siglo, Rojas denuncia el extravio: en $E l$ pais de la selva vuelve a la tradición y al paisaje como fuentes inspiradoras; en La restauración nacionalista urge a reformar nuestra educación en vista a los problemas concretos del país; en Blasón de plata se unen el rápsoda y el profeta para ahondar en el destino de nuestro pueblo. Y así, toda la obra de Rojas nace infundida por la misión de esclarecer los deberes nacionales: La argentinidad (1916), su magna Historia de la literatura argentina (1917-1920), Eurindia (1922), Las provincias (1926)...

Rojas enseña, aclara, avisa, denuncia. Sus propios discípulos difunden sus ideas y también, a veces, se convierten en violentos enemigos de sus doctrinas. Rojas acuña fórmulas y conceptos rectores. Pone en circulación palabras que adquieren empuje nacional, como "argentinidad" o "eurindia". Descifra leyendas y presagios. Desafía a quienes traicionan los ideales de Mayo. Si padece, su delito es de amor. Preso, canta en $\mathrm{El} \mathrm{al-}$ batros:

Vuelvo mis ojos a mi patria y grito:

Yo soy aquél que antaño te cantara,

y el amor que te dí fué mi delito.

La obra de Rojas es vastísima y abarca todos los géneros: el relato, la poesía lírica, el drama, la biografía, la oratoria, la crítica. Está en curso 
de publicación la segunda edición de sus Obras completas, que alcanzará a 40 volúmenes. Se dará el caso extraordinario en América de un escritor que asistió en vida a la reedición de su obra toda sin apoyo oficial, con la exclusiva ayuda de sus lectores.

En su larga existencia Rojas recibió la consagración del triunfo literario con la misma sencillez que soportó la corona de espinas del vejamen injusto. Le fue arrebatado el Premio Nacional de Letras, se persiguió policialmente a quienes solicitaban el Premio Nóbel para su obra. Por eso, al recibir de la Sociedad de Escritores el Premio de Honor, pronuncia palabras proféticas. No desea el oro que "respalda la fuga de los tiranos. El oro es metal del infierno. El bronce es el metal de la gloria".

La vida y los libros de Rojas constituyen una ratificación de las posibilidades mejores de nuestra patria. Mensajes del ayer, símbolos del presente, en su obra la Argentina está abarcada en plenitud. Su obra retoma la visión de una Argentina esperanzada y coherente, iluminada por la $\mathrm{fe}$ en su destino grande, fundado en la democtacia y en la libertad, sin concesiones a las ideologías del odio y de la muerte. Rojas no es un erudito frío ni su obra es letra muerta. Su palabra es un deber, una enseña de combate. Ricardo Rojas simboliza hoy las trágicas experiencias de nuestra nacionalidad, el sacrificio por consecuencia con valores inmarcesibles. Los argentinos volveremos una y otra vez, con renovada inquietud, a las páginas del maestro. He aquí el diálogo vivo de las generaciones, del que se nutre la verdadera historia.

Rojas ha recorrido ya, sencillamente, ese paso, a veces arduo, entre la muerte y la gloria. Apenas cerró los ojos éste a quien Unamuno llamó "tan hondo, $\tan$ noble y tan penetrante patriota argentino", y ya el país todo lo sintió como un pater patriae. Queda el monumento de su obra, de sus libros, de su ejemplo. Sin ellos, no podrá pensarse ni entenderse esto que llamamos la Argentina. Ricardo Rojas es ya, él mismo, un testimonio de la existencia de esa patria ideal a la que entregó sus sueños de poeta y sus dolores de patriota.

ANTonio Pagés Larraya, Universidad de Buenos Aires. 
